\title{
sciendo
}

UDK: 330.101 .541

DOI: $10.2478 / j c b t p-2019-0010$

Andrija Đurović *

\section{Macroeconomic Approach to Point in Time Probability of Default Modeling - IFRS 9 Challenges ${ }^{1}$}

\begin{abstract}
This paper aims to present one possible retail estimation framework of lifetime probability of default in accordance with IFRS 9. The framework rests on "term structure of probability of default" conditional to given forward-looking macroeconomic dynamics. Due to the one of the biggest limitation of forward-looking modelling - data availability, model averaging technique for quantification of macroeconomic effect on default probability is explained.
\end{abstract}

Key words: IFRS 9, Term Structure of Probability of Default, Point in Time Probability of Default, Forward-looking, Macroeconomic approach, Model averaging

JEL: G11, G23, C41

\section{Introduction}

In 2014, the International Accounting Standards Board (IASB) issued the completed version of International Financial Reporting Standard 9 (IFRS 9) which under impairment requirements requires the measurement of impairment loss provisions to be based on an expected credit loss $(E C L)$ accounting model rather than on an incurred loss accounting model. Additionally, banks were to measure the loss allowance equal to lifetime ECL for all financial instruments for which there have been significant increases in credit risk since initial recognition.

1 The views expressed in this paper are those of the author and do not necessarily reflect those of the employer. 
The key components of estimation ECL frameworks are term structure of probability of default (TsPD), loss given default ( $L G D)$, exposure at default $(E A D)$ and dynamic state of conditional variable (e.g. macroeconomic indicators). This paper focuses on perhaps the most important component of lifetime ECL -TsPD. Even though historical information is an important anchor or base from which to measure expected credit losses, an entity is to adjust historical data such as credit loss experience on the basis of current observable data to reflect the effects of the current conditions and its forecasts of future conditions that did not affect the period on which the historical data is based, and to remove the effects of the conditions in the historical period that are not relevant to the future contractual cash flows (B5.5.52, details of these requirements can be found in IASB [2014]). Translated to the main component of the paper, this means that historical unadjusted $P D$ through the cycle (TTC PD) should be modelled conditional to state variables, in order to forecast so called point-in-time PD (PIT PD).

Concept of PIT PD is not new in credit risk literature. It can be dated back to Belkin et al (1998) that proposed one-parameter representation of credit risk and transition matrices, and with the application of survival models for credit risk analysis started with the paper by Narain (1992) and, later, was developed by Carling et al (1998), Roszbach (2003), Glennon and Nigro (2005), Allen and Rose (2006), Baba and Goko (2006), and Malik and Thomas (2006).

Based on lessons learned from the financial crisis, Breeden (2010) proposed a reinvented approach for retail analytics utilizing from analysis of all available vintages simultaneously. He stated that consumer's risk of default exhibits strong lifecycle effects and decomposes vintage performance on maturation, exogenous (macroeconomic) and vintage quality effect. In response to upcoming regulatory standards, new age literature rapidly increases. Thus, Conze (2015) explores PIT PD modelling based on Asymptotic Single Risk Factor Model providing generalization of one-parameter model. Xu (2016) presents general framework estimation for lifetime ECL, discussing popular modelling strategies for the key components of this framework. Brunel (2016) provides a comprehensive survey of PD analytics methodology, clearly emphasizing the difference in approaches between retail and corporate analytics.

Selection of any proposed modelling technique is highly dependent on data availability. Concretely for macroeconomic PIT PD modelling, limitations can exist on TTC PD calibration side and on macroeconomic indicators availability. In situation where the ratio of data points to number of variables (macroeconomic indicators) is small, standard variable selection methods can often be misleading. This phenomenon is known as Freedman's paradox (Freedman, 1983) and cur- 
rently presents one of the biggest limitations for IFRS9 forward looking modelling. In order to overcome this problem, different statistical variations of model averaging estimators are proposed.

Lukacs et al (2010) proposed model averaging estimator based on model selection with Akaike's AIC used with linear regression. They found that the proposed model estimator reduces bias introduced while using data to select a single seemingly "best model" from a set of models employed in many predictor variables.

Similarly, Clemen (1989) and Stock and Watson (2001, 2004) undertook an extensive study across numerous economic and financial variables using linear and nonlinear forecasting models and found that, on average, pooled forecasts outperform predictions from the single best model. Timmermann (2005) exposed two main reasons for using forecast combinations. First, individual forecasts may be very differently affected by structural breaks caused, for example, by institutional change or technological developments. Some models may adapt quickly and will only temporarily be affected by structural breaks, while others have parameters that only adjust very slowly to new post-break data. The second reason is that individual forecasting models may be subject to misspecification bias of an unknown form (underlying data generating process and variable selection bias).

Finally, compliance with professional and legal regulations is not sufficient guarantee for ensuring quality of financial reporting. Ethical behavioural in the process of providing desired quality is recognized with its inescapable role (Todorović, 2018).

This paper provides an illustrative example of one possible approach to retail PIT $P D$ statistical modelling technique for different macroeconomic scenarios. It is motivated by credit risk analysis and requirements of IFRS 9. The remainder of the paper is organized as follows. Section 2 presents a data description and its development over years. Section 3 and 4 present the methodology applied and empirical results. Finally, conclusions are presented.

\section{Data description}

In this article, we analysed loans issued in the period from 2008 Q3 to 2016 Q4, from the world's largest USA online credit marketplace Lending Club. Since Lending Club allows for delinquency status, all loans with current status Late (31- 120 days), Default, Charged off are marked as defaulted. 
Total number of issued loans in analysed period is $1,317,974$. The number of loans with defaulted status is 142,125 . Figure 1 presents development of the analysed portfolio.

Figure 1: Modelling portfolio development
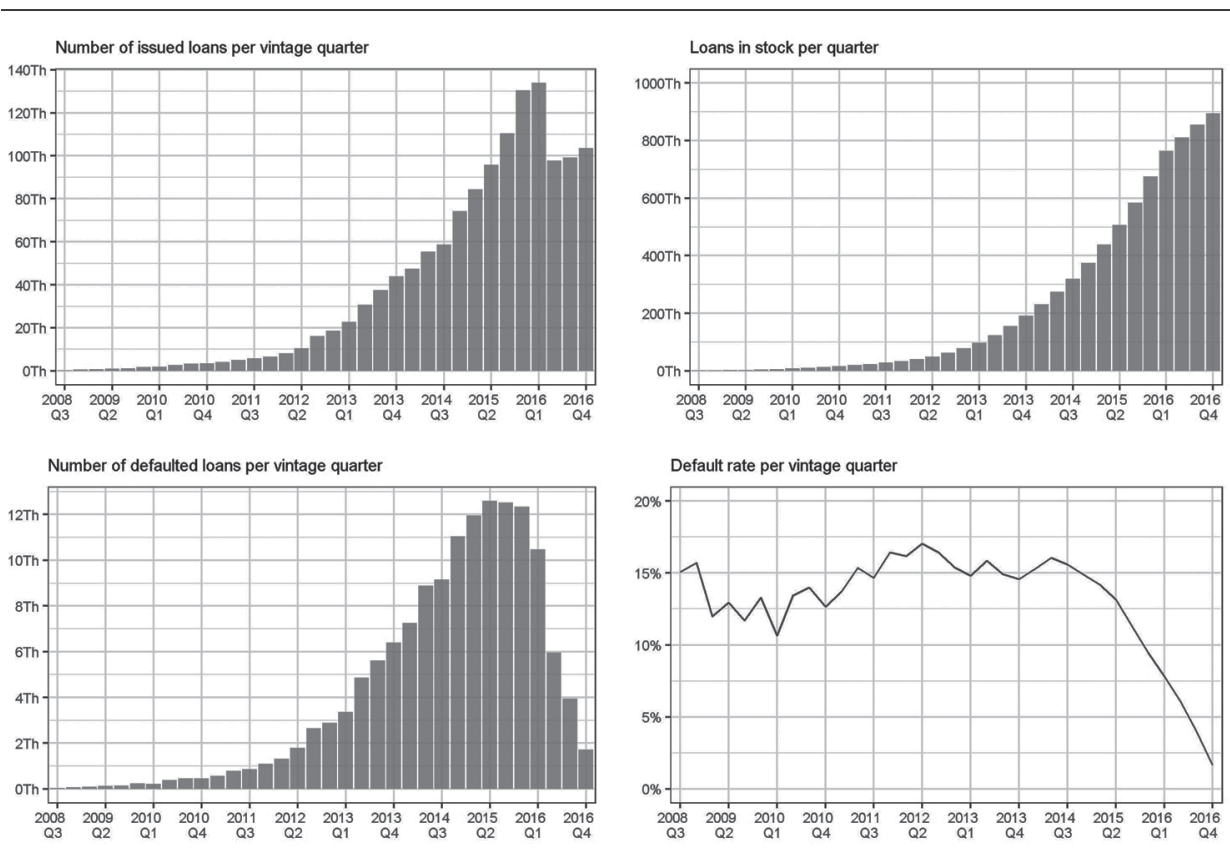

In 2016, the number of issued loans registered a decrease after a significant increase in 2015. An increase in the number of issued loans until 2016 was followed by an increase in the number of defaults but at quite steady default rate per quarter of around $14 \%$.

The USA macroeconomic indicators used for modelling are GDP growth rate, unemployment rate, FX rate, consumption, and consumer price index. They are downloaded from Federal Reserve Economic Database (FRED) for the period from 2008 Q3 to 2016 Q4.

Quarter-on-quarter observed default rate $(O D R)$ and development of macroeconomic indicators are presented in Figure 2. 
Figure 2: Observed default rate and macroeconomic indicators

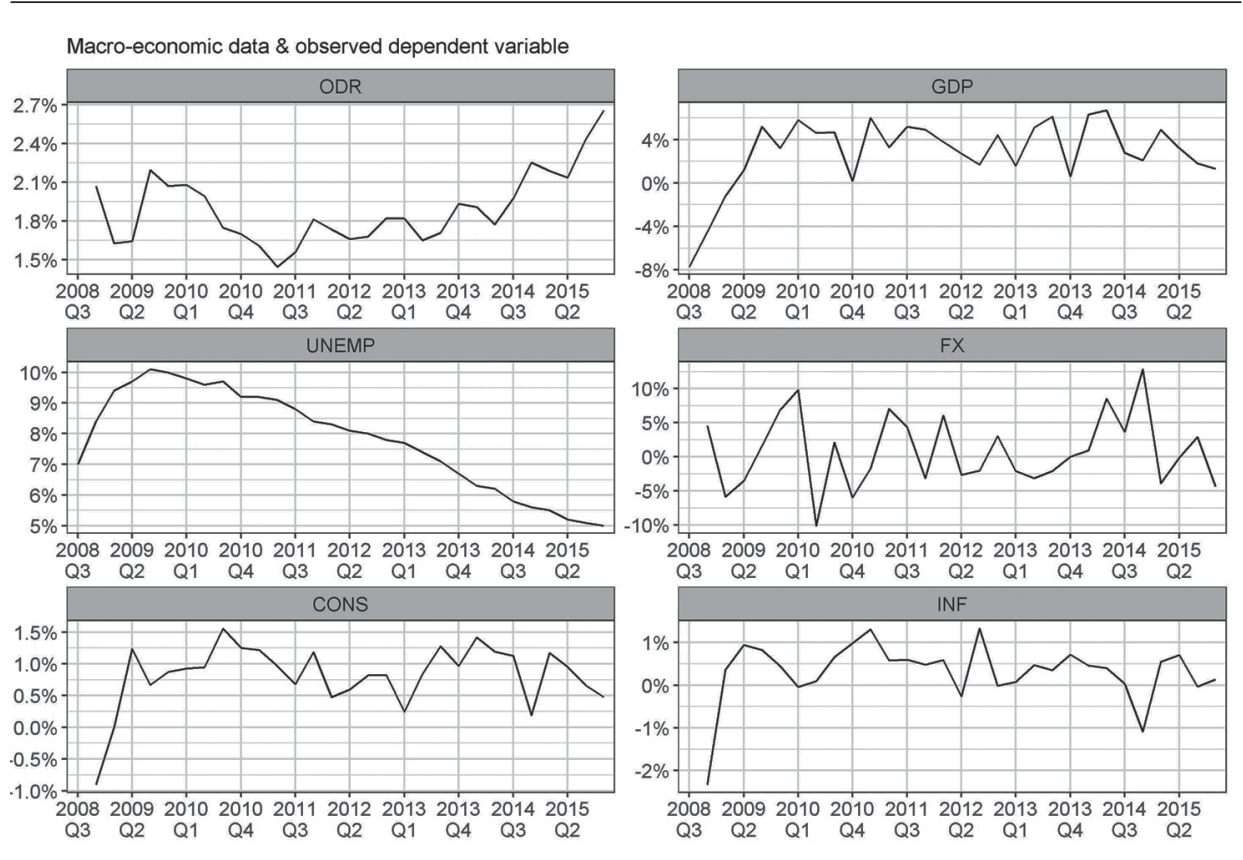

\section{Methodology}

\section{TTC framework}

Term structure of $P D$ presents the product of two components: the conditional $P D$ and the survival rate $(S R)$. Conditional $P D$ is calculated as the ratio between the number of defaults $(D)$ and population at risk $(R)$ for a certain period of time:

$P D_{t}=\frac{\sum_{i=t-1}^{t} D_{i}}{R_{t-1}}$

The survival rate expresses the probability that a certain loan is still at risk at any given period $t$. Depending of the ECL modelling approach, the survival rate can include all possible exits from the population at risk or only exits based on already defaulted accounts. We use the latter approach to calculate the survival rate employing the product-limit estimator. Survival function is given by following formula: 
$S R_{t}=\prod_{t_{i}<t}\left(1-P D_{t i}\right)$

Both parameters, $P D$ and $S R$, are estimated using cohort analysis based on "loans in stock", all loans at snapshot date that are not defaulted. Cohorts are formed on quarterly bases and TTC PD is calculated as an average of cohorts $P D$ for all available quarters. In total we have 36 cohorts with time window from 36 to one quarter. Tables 1 to 5 present the examples of the parameters calculation:

Table 1: Number of defaults in horizon view

\begin{tabular}{ccccccc}
\hline Snapshot & Q1 & Q2 & Q3 & Q4 & $\ldots$ & Q36 \\
\hline 2008 Q3 & 10 & 15 & 17 & 8 & & 1 \\
\hdashline 2008 Q4 & 12 & 20 & 25 & 17 & & \\
\hdashline$\ldots$ & & & & & & \\
\hline
\end{tabular}

Table 2: Population at risk in horizon view

\begin{tabular}{ccccccc}
\hline Snapshot & Q1 & Q2 & Q3 & Q4 & $\ldots$ & Q36 \\
\hline 2008 Q3 & 2000 & 1750 & 1400 & 1200 & & 100 \\
\hdashline 2008 Q4 & 2500 & 2350 & 2100 & 1950 & & \\
\hline
\end{tabular}

Table 3: Conditional probability of default

\begin{tabular}{ccccccc}
\hline Snapshot & Q1 & Q2 & Q3 & Q4 & $\ldots$ & Q36 \\
\hline 2008 Q3 & $0.50 \%$ & $0.86 \%$ & $1.21 \%$ & $0.67 \%$ & & $1.00 \%$ \\
\hline 2008 Q4 & $0.48 \%$ & $0.85 \%$ & $1.19 \%$ & $0.87 \%$ & & \\
\hdashline$\ldots$ & & & & & & \\
\hline
\end{tabular}

Table 4: TTCPD

\begin{tabular}{cccccc}
\hline Q1 & Q2 & Q3 & Q4 & $\ldots$ & Q36 \\
\hline $0.49 \%$ & $0.85 \%$ & $1.20 \%$ & $0.77 \%$ & & $1.00 \%$ \\
\hline
\end{tabular}

Table 5: TTCSR

\begin{tabular}{cccccc}
\hline Q1 & Q2 & Q3 & Q4 & $\ldots$ & Q36 \\
\hline $100 \%$ & $99.51 \%$ & $98.66 \%$ & $97.96 \%$ & $\ldots$ & $\ldots$ \\
\hline
\end{tabular}




\section{PIT (forward-looking) framework}

In the next step we adjust TTC PD to PIT PD based on changes of macroeconomic indicators. For this purpose we calibrate the "alpha" parameter which measures where we are in the credit cycle and drives how much we shift the PIT PD from TTC PD (Cheong et al, 2017):

$O D R_{q}=\frac{1}{1+\left\{\frac{O D R_{L T}}{1-O D R_{L T}}\right\}^{-a l p h a}}$

where $O D R_{q}$ presents short term (quarterly) observed default rate and $O D R_{L T}$ presents long-term default rate. The lowest possible value of the alpha parameter indicates that recent defaults significantly exceed long-term defaults and the credit cycle is in a steep downturn.

TTC PD is mapped to PIT PD using calculated alpha parameter for all forecasted periods:

PIT PD $=\frac{1}{1+\left\{\frac{T T C P D_{t}}{1-T T C P D_{t}}\right\}^{-a l p h a}}$

and finally, PIT Ts $P D_{t}$ given $P I T P D_{t}$ is:

PIT TsPD $D_{t}=\prod_{t_{i}<t}\left(1-P I T P D_{t i}\right) * P I T P D_{t}$

In order to obtain forecast of $O D R_{q}$ we estimate linear regression models where we use the following macroeconomic indicators as independent variables: yearly GDP growth (GDP), unemployment rate (UNEMP), quarterly consumption change (CONS), quarterly change of FX rate (FX), quarterly inflation (INF). All possible linear models of one, two, and three independent variables combination, with time lags from one to four quarters, are fit. Variables are modelled in the first difference due to non-stationarity property of $O D R_{q}$ (KPPS p-value $4 \%$, PP p-value 70\%, ADF p-value 96\%) ${ }^{2}$. If the estimated model has Durbin-Watson p-value less than $5 \%$, heteroscedasticity and autocorrelation consistent standard errors are calculated and coefficient significance is reviewed based on this standard errors. Out of all estimated models, we selected only the models that fulfil the following criteria:

2 KPPS - Kwiatkowski-Phillips-Schmidt-Shin tests, PP - Phillips-Perron test, ADF - Augmented Dickey-Fuller test 
1. Estimated sign of independent variable is in line with economic expectations: GDP - negative, UNEMP- positive, CONS - negative, FX - positive, INF - positive.

2. All estimated coefficients are statistically significant at $5 \%$ significance level.

3. Shapiro-Wilk p-value test for residual normality is lower than $5 \%$.

4. No multicollinearity exists measured by variance inflation factor less than 5 .

Based on selected models and assumed forecasts of macroeconomic indicators, we forecast $O D R_{q}$ for $n$ quarters ahead. Further, we calculate the weighted average of each model forecast, following the approach of Lukacs et al (2010) except that the original AIC value is used.

Weights calculation starts with an estimate of Kullback-Leibler information loss:

$\Delta_{j}=A I C_{j}-\min \left(A I C_{j}\right)$

Then Akaike weight for selected model $\mathrm{j}$ is calculated as:

$w_{j}=\frac{\exp \left(-\frac{1}{2} \Delta_{j}\right)}{\sum_{j=1}^{R} \exp \left(-\frac{1}{2} \Delta_{j}\right)}$

Finally, weighted ODRq is obtained:

$\widehat{O D R}_{q}=\sum_{j=1}^{R} w_{j} * O D R_{q j, t}$

After we obtain $O D R_{q}$, the alpha parameter is calibrated and final PIT PD adjustment is done (Eq. 4).

Since forecast of macroeconomic indicator is beyond the aim of this paper and for the sake of simplicity, we split data on estimation and forecasting data set. Forecasting data set consists of last four observations (four quarters of 2016) and the baseline scenario is equal to observed figures of macroeconomic indicators. Pessimistic scenario is simulated based on the last four observed figures. GDP is assumed to decrease by $1 \%$, UNEMP increased by $20 \%$, FX increases by $20 \%$ or remain at $0 \%$ change (depending on previous year changes), while INF increases by $20 \%$ for each quarter. Table 6 summarises assumed forecasted figures: 
Table 6: Assumed macroeconomic forecasts for baseline and pessimistic scenarios

\begin{tabular}{ccccccc}
\hline Quarter & GDP & UNEMP & FX & CONS & INF & Scenario \\
\hline 2016 Q1 & $3.70 \%$ & $5.00 \%$ & $2.55 \%$ & $1.56 \%$ & $0.34 \%$ & Base \\
\hline 2016 Q2 & $5.00 \%$ & $5.00 \%$ & $-0.52 \%$ & $1.10 \%$ & $0.41 \%$ & Base \\
\hline 2016 Q3 & $4.20 \%$ & $4.80 \%$ & $5.88 \%$ & $1.37 \%$ & $0.75 \%$ & Base \\
\hline 2016 Q4 & $3.40 \%$ & $4.70 \%$ & $-1.40 \%$ & $0.67 \%$ & $1.02 \%$ & Base \\
\hline 2016 Q1 & $-1.00 \%$ & $6.00 \%$ & $3.06 \%$ & $1.25 \%$ & $0.40 \%$ & Pessimistic \\
\hline 2016 Q2 & $-1.00 \%$ & $6.00 \%$ & $0.00 \%$ & $0.88 \%$ & $0.50 \%$ & Pessimistic \\
\hline 2016 Q3 & $-1.00 \%$ & $5.76 \%$ & $7.06 \%$ & $1.10 \%$ & $0.90 \%$ & Pessimistic \\
\hline 2016 Q4 & $-1.00 \%$ & $5.64 \%$ & $0.00 \%$ & $0.54 \%$ & $1.22 \%$ & Pessimistic \\
\hline
\end{tabular}

\section{Empirical results}

Figure 3 presents TTC parameters calibrated within framework explained in methodology section: conditional $P D$, survival rate $S R$ and TsPD.

Figure 3: TTC framework

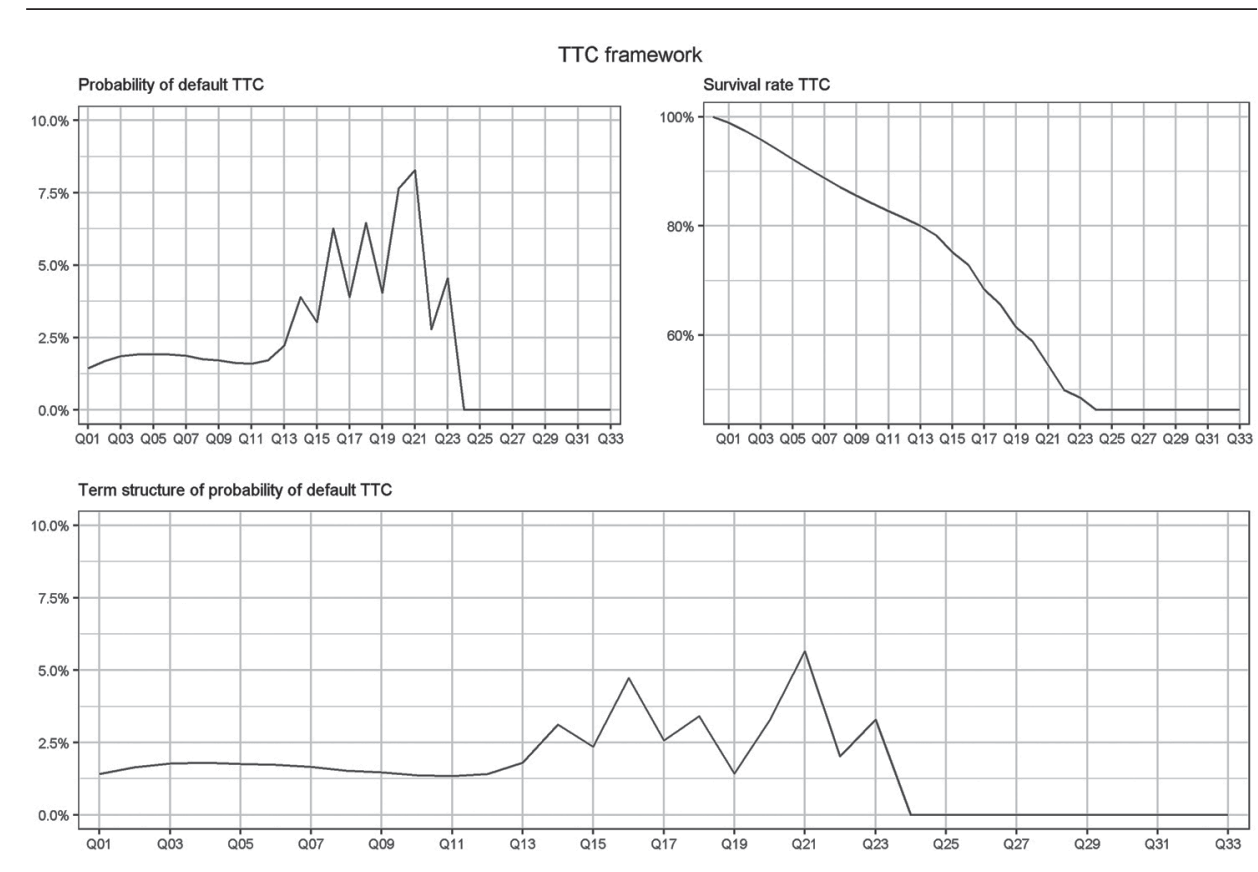


Due to the high prepayment rate after $11^{\text {th }}$ quarter, certain noise is easy noticeable in calibrated parameters. This phenomenon confirms specificity of retail loans compared to corporate loans already noticed by Brunel (2016) and Breeden (2010). In addition to prepayment specificity, maturation effect is present as well even though conditional $P D$ is calibrated based on "loans in stock".

Out of all estimated models, only three single factor models fulfil the selected criteria and they are presented in Table 7.

Table 7: Selected candidate models

\begin{tabular}{llrrrrrrrr}
\hline Model_ID & Coefficients & Estimate & StdError & t-value & Prt & $\begin{array}{c}\mathrm{R} \\
\text { squared }\end{array}$ & $\begin{array}{c}\text { SW } \\
\text { p-value }\end{array}$ & $\begin{array}{c}\text { AIC } \\
\text { p-value }\end{array}$ \\
\hline $\mathrm{d}(\mathrm{ODR})-1-M o d e l: 15$ & $\operatorname{lag}(\mathrm{d}(\mathrm{INF}),-2)$ & 0.11 & 0.04 & 2.80 & $0.97 \%$ & $23.86 \%$ & $12.09 \%$ & -256.29 & $78.60 \%$ \\
\hline $\mathrm{d}(\mathrm{ODR})-1-M o d e l: 21$ & $\operatorname{lag}(\mathrm{d}(\mathrm{GDP}),-4)$ & -0.02 & 0.01 & -2.65 & $1.40 \%$ & $22.64 \%$ & $61.72 \%$ & -255.19 & $66.80 \%$ \\
\hdashline $\mathrm{d}($ ODR)-1-Model:4 & $\mathrm{d}(\mathrm{CONS})$ & -0.17 & 0.07 & -2.51 & $1.85 \%$ & $18.87 \%$ & $59.94 \%$ & -271.09 & $83.00 \%$ \\
\hline
\end{tabular}

Figures 4 and 5 present forecast of default rate as the weighted average of selected models and forecast of default rate for each model separately.

Figure 4: Forecast of observed default rate for base and pessimistic scenario

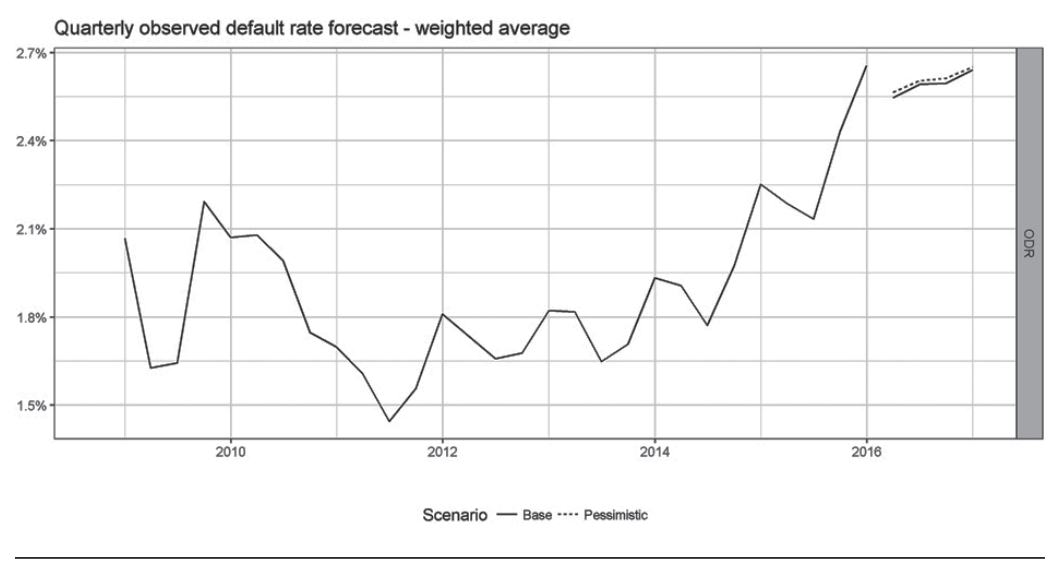


Figure 5: Forecast of observed default rate for each model and two scenarios

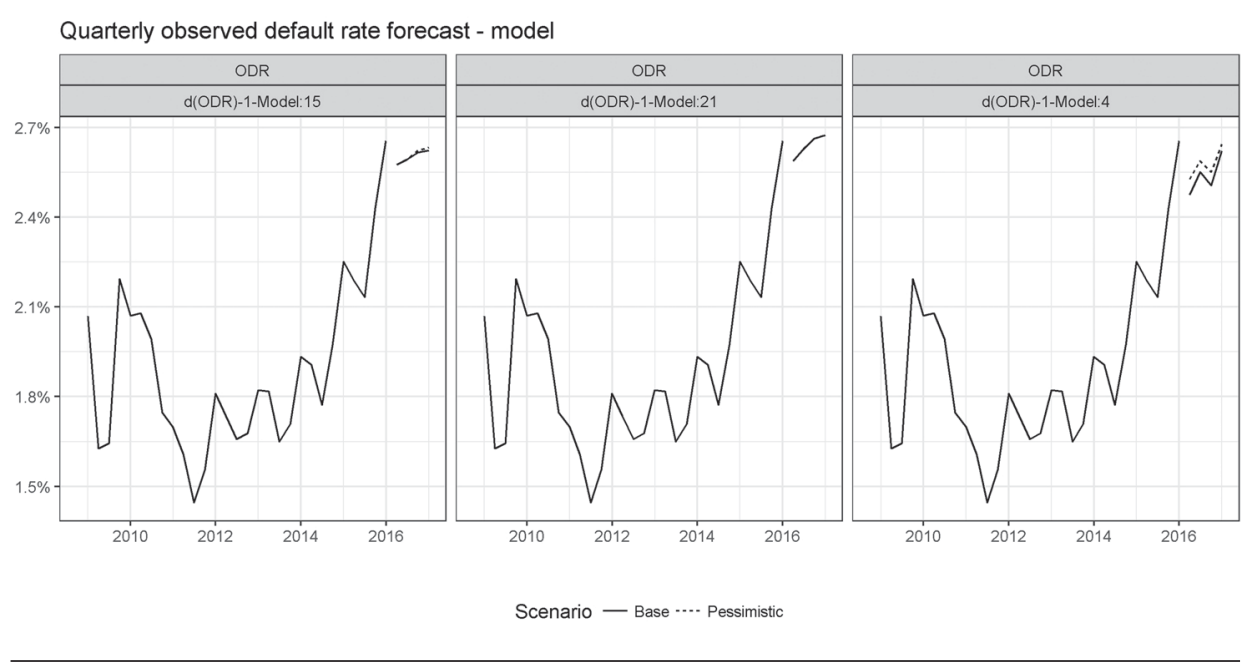

Due to the low sensitivity of $O D R_{q}$ to macro environment, forecasts of both scenarios are close to each other despite the fact of assumed high change in pessimistic scenario. The main reason for this is the fast growing and changing Lending Club portfolio, so the more important effect on default rate have internal changes over macro environment.

Once the forecast of $O D R_{q}$ are obtained, PIT PD $t$ and $P I T T s P D_{t}$ can be calibrated. Under assumption that macro environment has the same effect on the portfolio regardless of the portfolio maturity, calibrated PIT $P D_{t}$ and $P I T T s P D_{t}$ are presented in Table 8 and Figure 6.

Table 8: $P I T P D_{t}$ and $P I T T S P D_{t}$ calibration

\begin{tabular}{lccccccc}
\hline Scenario & Quarter & Forecast & ODRLT & alpha & TTC PD & PIT PD & PIT TsPD \\
\hline Base & $2016-03-31$ & $2.48 \%$ & $1.89 \%$ & 0.9303 & $1.43 \%$ & $1.92 \%$ & $1.92 \%$ \\
\hdashline Base & $2016-06-30$ & $2.55 \%$ & $1.89 \%$ & 0.9224 & $1.68 \%$ & $2.29 \%$ & $2.25 \%$ \\
\hdashline Base & $2016-09-30$ & $2.51 \%$ & $1.89 \%$ & 0.9271 & $1.85 \%$ & $2.46 \%$ & $2.36 \%$ \\
\hdashline Base & $2016-12-31$ & $2.62 \%$ & $1.89 \%$ & 0.9153 & $1.92 \%$ & $2.66 \%$ & $2.49 \%$ \\
\hline Pessimistic & $2016-03-31$ & $2.53 \%$ & $1.89 \%$ & 0.9249 & $1.43 \%$ & $1.96 \%$ & $1.96 \%$ \\
\hdashline Pessimistic & $2016-06-30$ & $2.59 \%$ & $1.89 \%$ & 0.9187 & $1.68 \%$ & $2.33 \%$ & $2.28 \%$ \\
\hdashline Pessimistic & $2016-09-30$ & $2.55 \%$ & $1.89 \%$ & 0.9224 & $1.85 \%$ & $2.50 \%$ & $2.40 \%$ \\
\hdashline Pessimistic & $2016-12-31$ & $2.65 \%$ & $1.89 \%$ & 0.9130 & $1.92 \%$ & $2.68 \%$ & $2.50 \%$ \\
\hline
\end{tabular}


Figure 6: $P I T P D_{t}$ and $P I T T S P D_{t}$ calibration based on model average approach
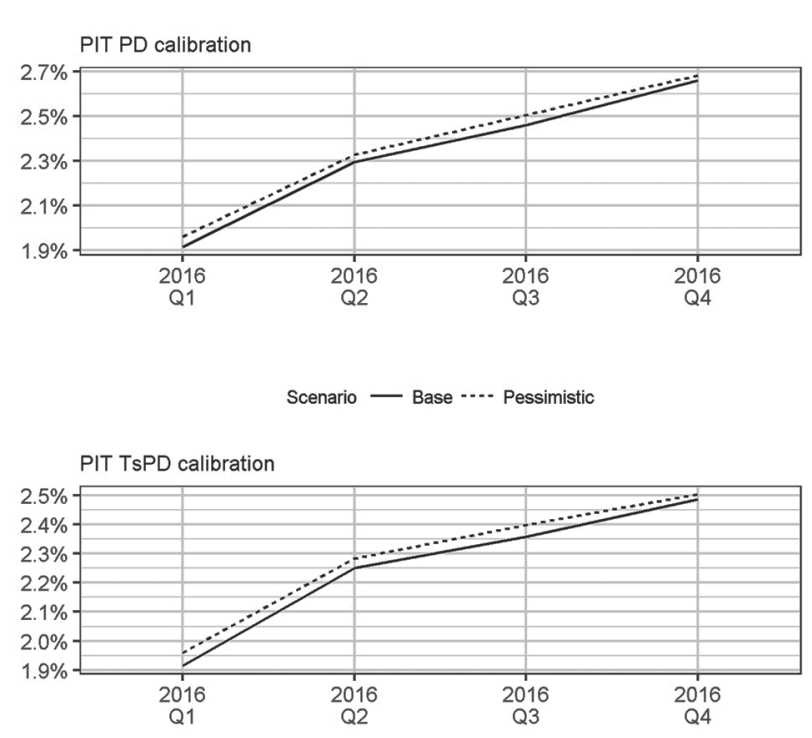

Scenario - Base -... Pessimistic

\section{Conclusion}

The upcoming IFRS9 standard requires each entity to adjust historical data on the basis of current observable data to reflect the effects of the current conditions and its forecasts of future conditions. In line with that, the aim of this paper was to provide an illustrative example of one possible macroeconomic approach to retail PIT PD statistical modelling technique. For that purposes we used data from the world's largest USA online credit marketplace Lending Club and USA macroeconomic indicators.

We presented the modelling approach proposed by Clemen (1989), Stock and Watson (2001, 2004), Timmermann (2005) and Lukacs et al. (2010) for the situation of limited data availability and possible structural break existence. Also, we take into account the specificity of retail loans (prepayment and maturation effect) already emphasized by Brunel (2016) and Breeden (2010). These specificities are incorporated in the TTC calibration framework. 
Finally, we found low effect of macro environment on $P D$ development mainly due to fast changing marketplace and a constant increase in the number of participants on this market. 


\section{References}

1. Allen, L. N. and Rose, L. C. (2006), Financial survival analysis of defaulted debtors, Journal of Operational Research Society, 57, 630-636.

2. Baba, N. and Goko, H. (2006), Survival analysis of hedge funds, Bank of Japan, Working Papers Series No. 06er S

3. Belkin, B., Suchower, S., Forest, L. R. (1998), A one-parameter representation of credit risk and transition matrices. Working paper, KPMG Peat Marwick LLP

4. Breeden, J. L. (2010), Reinventing Retail Lending Analytics: Forecasting, Stress Testing, Capital, and Scoring for a World of Crises. Risk books, London

5. Brunel, V. (2016), Lifetime PD Analytics for Credit Portfolios: Retrieved from: https://ssrn.com/abstract=2857183

6. Carling, K., Jacobson, T. and Roszbach, K. (1998), Duration of consumer loans and bank lending policy: dormancy versus default risk, Working Pap eries in Economics and Finance No. 280, Stockholm School of Economics.

7. Cheong, M., Tripolitakis, G., Ma, H., (2017), Using CreditPro To Measure Credit Losses In Investment Portfolios For IFRS 9 And CECL Requirements, Retrieved from: https://marketintelligence.spglobal.com/documents/ourthinking/research/IFRS9_CECL_Requirements_Whitepaper_June2017.pdf

8. Clemen, R.T., (1989), Combining Forecasts: A Review and Annotated Bibliography. International Journal of Forecasting 5, 559-581.

9. Conze, A. (2015), Probabilities of Default for Impairment Under IFRS 9. Retrieved from: https://ssrn.com/abstract=2685099

10. Freedman, D.A. (1983), A note on screening regression equations. The American Statistician 37: 152-155

11. Glennon, D. and Nigro, P. (2005), Measuring the default risk of small business loans: a survival analysis approach, Journal of Money, Credit, and Banking, 37, 923-947.

12. IASB, (2014), International Financial Reporting Standard 9 Financial instruments, International Accounting Standards Board.

13. Lukacs P.M., Burnham K.P., Anderson D.R. (2010), Model selection bias and Freedman's paradox, Ann Inst Stat Math 62:117-125

14. Malik, M. and Thomas L. (2006), Modelling credit risk of portfolio of consumer loans, University of Southampton, School of Management Working Paper Series No. CORMSIS-07-12.

15. Narain, B. (1992). Survival analysis and the credit granting decision. In: Thomas L., Crook, J. N. And Edelman, D. B. (eds.). Credit Scoring and Credit Control. OUP: Oxford, 109-121. 
16. Roszbach, K. (2003). Bank lending policy, credit scoring and the survival of loans, Sverriges Riksbank Working Paper Series No. 154.

17. Stock, J.H., Watson M., (2004), Combination Forecasts of Output Growth in a Seven-Country Data Set. Journal of Forecasting 23, 405-430

18. Stock, J.H., Watson, M., (2001), A Comparison of Linear and Nonlinear Univariate Models for Forecasting Macroeconomic Time Series. Pages 1-44 In R.F. Engle and H. White (eds).

19. Timmermann, A.G., (2005), Forecast Combinations CEPR Discussion Paper No. 5361. Retrieved from: https://ssrn.com/abstract $=878546$

20. Todorovic, Z. (2018), Application of Ethics in the Accounting Profession with an Overview of the Banking Sector, Journal of Central Banking Theory and Practice, 2018, 3, pp. 139 - 158

21. Xu, X. (2016), Estimating Lifetime Expected Credit Losses Under IFRS 9, Retrieved from http://papers.ssrn.com/sol3/papers.cfm?abstract_id=2758513 